\title{
Calibration Fluids and Calibration Equations: How Choices May Affect the Results of Density Measurements Made with U-Tube Densimeters
}

\author{
Stephanie L. Outcalt \\ National Institute of Standards and Technology, \\ Boulder, CO 80305, USA \\ outcalt@nist.gov
}

\begin{abstract}
Data on the calibration fluids water and toluene individually, and the combination of those two sets of data, were correlated with two different equations (resulting in six sets of calibration equation parameters) to analyze data measured with a vibrating-tube densimeter on the lubricants pentaerythritol tetrapentanoate (POE5), pentaerythritol tetraheptanoate (POE7), and pentaerythritol tetranonanoate (POE9) at temperatures from $270 \mathrm{~K}$ to $470 \mathrm{~K}$ and pressures from $0.5 \mathrm{MPa}$ to $50 \mathrm{MPa}$. The objective was to explore how the calculated densities of the lubricants would differ based on the calibration equations and calibration fluid(s). The viscosities of the measured lubricants are much greater than those of the calibration fluids, and because there has long been a question of how measurements of higher viscosity fluids are affected when measured with a vibrating-tube densimeter, combinations of calibration fluid(s) and equations were tested to explore the role they play in obtaining accurate results. For the lubricants studied herein, more accurate results were obtained with a calibration fitted to multiple calibration fluids, while the consistency of results was more equation dependent.
\end{abstract}

Key words: calibration; density; U-tube densimeter; vibrating-tube densimeter.

Accepted: September 19, 2018

Published: October 9, 2018

https://doi.org/10.6028/jres.123.017

\section{Introduction}

Today, vibrating-tube densimeters are commercially available and frequently used in industry, academia, and national laboratories. The variety of fluids measured with vibrating-tube densimeters is ever increasing. Fluids as simple as alcohols to highly complex fluids such as alternative fuels are measured with these instruments. The density measurements made with this technique are not absolute. The instruments must be adjusted based on measurements of calibration fluids. Measurements of the temperature $(T)$, pressure $(p)$, and period of oscillation of the vibrating U-tube $(\tau)$ filled with the calibration fluid(s) at various temperatures and pressures are the core of the adjustment procedure. Densities of the calibration fluid(s) are then calculated from associated correlations. Ideally, fluids used for calibration are certified reference materials (CRMs) or fluids that have highly accurate equations of state associated with 
them. The calibration fluid(s) data are then used to correlate parameters for a given calibration equation where density is a function of temperature, pressure, and the period of oscillation of the U-tube.

Several journal articles have been published with suggested calibration fluids and functional forms for the calibration equation [1-6]. The manufacturers of the instruments typically suggest a polynomial expansion in temperature and pressure to represent density, while other equations are based on theoretical models of the physics of vibrating objects. The accuracy of density measurements depends largely on the accuracy of the densities of the calibration fluid(s) and how well the calibration data in conjunction with the calibration equation model the behavior of the U-tube when it is filled with the sample being measured.

The goal of this work was to examine how using one or two calibration fluids (in addition to vacuum) to determine the parameters of a calibration equation would affect the densities that were calculated for a set of lubricants. Water and toluene (NIST SRM 211D) were the two calibration fluids used. Two equations were used: the May et al. [1] equation, which is based on the physical characteristics of the tube and its vibrational modes, and a nine-term polynomial expansion in temperature and pressure. Six sets of calibration equation parameters were determined: three sets for the May et al. [1] equation, and three sets for the nine-term polynomial. For both the May et al. [1] equation and the nine-term equation, parameters were determined using (1) water only, (2) toluene only, and (3) water and toluene data combined.

\section{Experimental}

The vibrating-tube densimeter of Outcalt and McLinden [7] was used to measure compressed-liquid densities of the fluids pentaerythritol tetrapentanoate (POE5), pentaerythritol tetraheptanoate (POE7), and pentaerythritol tetranonanoate (POE9) within a temperature range of $270 \mathrm{~K}$ to $470 \mathrm{~K}$ at pressures within $0.5 \mathrm{MPa}$ to $50 \mathrm{MPa}$. The results of those measurements have been published by Outcalt [8]. Tables 1 and 2 list the temperature and pressure ranges of the measurements of the calibration fluids and the lubricants measured in that study. To summarize the data, the compressed-liquid densities of the lubricants studied cover a density range from $829 \mathrm{~kg} \cdot \mathrm{m}^{-3}$ to $1063 \mathrm{~kg} \cdot \mathrm{m}^{-3}$ with the densities of POE5 > POE7 > POE9 for similar state points. The overall combined uncertainty of the measurements was calculated to be $0.7 \mathrm{~kg} \cdot \mathrm{m}^{-3}$ to $0.8 \mathrm{~kg} \cdot \mathrm{m}^{-3}$ at $T<423 \mathrm{~K}$ and $1.1 \mathrm{~kg} \cdot \mathrm{m}^{-3}$ to $1.2 \mathrm{~kg} \cdot \mathrm{m}^{-3}$ at $T \geq 423 \mathrm{~K}$ (level of confidence $=0.95$ ). Measurements of the POE7 and POE9 samples were fewer because the normal melting points of those lubricants were high enough that the sample was solidifying in the lower temperature and higher pressure ranges. Hence, no measurements were made in those regions.

Table 1. List of calibration data: number of points, temperature range, pressure range, and density range.

\begin{tabular}{ccccc}
\hline Calibration Fluid & Points Measured & Temperature Range $(\mathrm{K})$ & Pressure Range $(\mathrm{MPa})$ & Density Range $\left(\mathrm{kg} \cdot \mathrm{m}^{-3}\right)$ \\
\hline Vacuum & 11 & $270-470$ & 0.0 & 0.0 \\
Toluene & 142 & $270-470$ & $0.5-50$ & $681-917$ \\
Water & 104 & $290-470$ & $2-45$ & $869-1019$ \\
\hline
\end{tabular}

Table 2. List of lubricant data: number of points, temperature range, pressure range, and density range.

\begin{tabular}{ccccc}
\hline Lubricant & Points Measured & Temperature Range $(\mathrm{K})$ & Pressure Range $(\mathrm{MPa})$ & Density Range $\left(\mathrm{kg} \cdot \mathrm{m}^{-3}\right)$ \\
\hline POE5 & 165 & $270-470$ & $0.5-50$ & $876-1063$ \\
POE7 & 161 & $270-290$ & $0.5-40$ & \\
& & $310-470$ & $0.5-50$ & $846-1012$ \\
POE9 & 145 & 290 & $0.5-25$ & \\
& & $310-470$ & $0.5-50$ & $828-971$ \\
\hline
\end{tabular}




\subsection{Calibration Equations}

The two equations used to represent the calibration data were the May et al. equation [1] and a nineterm polynomial expansion in temperature and pressure. The nine-term polynomial is given as Eq. (1).

$$
\rho=\left(C_{1}+C_{2} T+C_{3} t T^{2}+C_{4} p+C_{5} T p\right) \frac{\tau^{2}}{\tau_{0}^{2}}-\left(C_{6}+C_{7} t T^{2}+C_{8} p+C_{9} T p\right)
$$

In Eq. (1), $\mathrm{C}_{1}$ to $\mathrm{C}_{9}$ are correlating parameters, $p$ is pressure, $\tau$ is the period of oscillation of the vibrating U-tube, and $T$ is temperature. The value of $\tau_{0}$ was determined through fitting vacuum data at temperatures from $270 \mathrm{~K}$ to $470 \mathrm{~K}$ to a second-order polynomial in temperature as in Eq. (2).

$$
\tau_{0}=A_{1}+A_{2} T+A_{3} t T^{2}
$$

The May et al. equation [1] is shown as Eq. (3). $S_{00}, \alpha_{V}, \beta_{V}$, and $\beta_{\tau}$ are correlating parameters, $\rho_{M}$ is the density of Hastelloy (the material from which the U-tube is constructed), and $p, \tau$, and $T$ are pressure, the period of oscillation of the vibrating U-tube, and temperature, respectively.

$$
\rho=\frac{\left(\rho_{M} / S_{00}\right)}{\left(1+\alpha_{V} t+\beta_{V} p\right)} \cdot\left(\left(\frac{\tau}{\tau_{00}\left(1+\varepsilon_{\tau 1} T+\varepsilon_{\tau 2} T^{2}\right)}\right)^{2}\left(1+\beta_{\tau} p\right)-1\right)
$$

In Eq. (3), the parameters of the expression $\tau_{00}\left(1+\varepsilon_{\tau 1} T+\varepsilon_{\tau 2} T^{2}\right)$ were determined by a linear least squares regression of data measured with the U-tube under vacuum. The expression thus gives the period of oscillation of the U-tube at vacuum as a function of temperature. This is the equivalent of $\tau_{0}$ in Eq. (1).

\subsubsection{Determination of Calibration Equation Parameters}

To determine the parameters $C_{1}$ to $C_{9}$ in Eq. (1), the parameters for Eq. (2) were determined first. Data with the U-tube under vacuum at temperatures from $270 \mathrm{~K}$ to $470 \mathrm{~K}$ (in $20 \mathrm{~K}$ increments) were correlated to the second-order polynomial through a least squares fit. Those coefficients are given in Table 3 .

Table 3. List of parameters for Eq. (2).

\begin{tabular}{cc}
\hline Parameter & Value \\
\hline $\mathrm{A}_{1}$ & 2394.040 \\
$\mathrm{~A}_{2}\left(\mathrm{~K}^{-1}\right)$ & $2.430445 \mathrm{E}-01$ \\
$\mathrm{~A}_{3}\left(\mathrm{~K}^{-2}\right)$ & $1.239389 \mathrm{E}-04$ \\
\hline
\end{tabular}

Three sets of parameters $\mathrm{C}_{1}$ to $\mathrm{C}_{9}$ were determined through orthogonal distance regression (ODR) [9]. The sets were determined using (1) water, (2) toluene, and (3) water and toluene data combined, as well as the vacuum correlation (in all three instances). Parameters for these fits are given in Table 4.

Table 4. Equation (1) parameters for the different calibration fluid(s).

\begin{tabular}{lccc}
\hline & Water & Toluene & Water + Toluene \\
\hline $\mathrm{C}_{1}\left(\mathrm{~g} \cdot \mathrm{cm}^{-3}\right)$ & $0.782164 \mathrm{E}+01$ & $0.856285 \mathrm{E}+01$ & $0.989918 \mathrm{E}+01$ \\
$\mathrm{C}_{2}\left(\mathrm{~g} \cdot \mathrm{cm}^{-3} \cdot \mathrm{K}^{-1}\right)$ & $0.179595 \mathrm{E}-03$ & $-0.262316 \mathrm{E}-03$ & $-0.390335 \mathrm{E}-04$ \\
$\mathrm{C}_{3}\left(\mathrm{~g} \cdot \mathrm{cm}^{-3} \cdot \mathrm{K}^{-2}\right)$ & $-0.115493 \mathrm{E}-06$ & $0.385759 \mathrm{E}-05$ & $-0.288184 \mathrm{E}-06$ \\
$\mathrm{C}_{4}\left(\mathrm{~g} \cdot \mathrm{cm}^{-3} \cdot \mathrm{kPa}^{-1}\right)$ & $0.608349 \mathrm{E}-05$ & $-0.775858 \mathrm{E}-05$ & $-0.298503 \mathrm{E}-05$ \\
$\mathrm{C}_{5}\left(\mathrm{~g} \cdot \mathrm{cm}^{-3} \cdot \mathrm{K}^{-1} \cdot \mathrm{kPa}^{-1}\right)$ & $-0.255391 \mathrm{E}-07$ & $0.745725 \mathrm{E}-08$ & $0.757917 \mathrm{E}-08$ \\
$\mathrm{C}_{6}\left(\mathrm{~g} \cdot \mathrm{cm}^{-3}\right)$ & $0.763141 \mathrm{E}+01$ & $0.838797 \mathrm{E}+01$ & $0.989178 \mathrm{E}+01$ \\
$\mathrm{C}_{7}\left(\mathrm{~g} \cdot \mathrm{cm}^{-3} \cdot \mathrm{K}^{-2}\right)$ & $0.361369 \mathrm{E}-06$ & $0.393487 \mathrm{E}-05$ & $-0.329053 \mathrm{E}-06$ \\
$\mathrm{C}_{8}\left(\mathrm{~g} \cdot \mathrm{cm}^{-3} \cdot \mathrm{kPa}^{-1}\right)$ & $0.666525 \mathrm{E}-05$ & $-0.854168 \mathrm{E}-05$ & $-0.318754 \mathrm{E}-05$ \\
$\mathrm{C}_{9}\left(\mathrm{~g} \cdot \mathrm{cm}^{-3} \cdot \mathrm{K}^{-1} \cdot \mathrm{kPa}^{-1}\right)$ & $-0.280433 \mathrm{E}-07$ & $0.842879 \mathrm{E}-08$ & $0.834497 \mathrm{E}-08$ \\
\hline
\end{tabular}


Parameters for the May et al. [1] equation were also determined with the ODR method [9]. The $\tau_{0}$ values determined at each temperature from Eq. (2) were used in place of the $\tau_{00}\left(1+\varepsilon_{\tau 1} T+\varepsilon_{\tau 2} T^{2}\right)$ expression, such that only four parameters $\left(S_{00}, \alpha_{V}, \beta_{V}, \beta_{\tau}\right)$ were fit for each combination of calibration data. Parameters determined for the May et al. [1] equation with the same calibration data sets as for Eq. (1) are listed in Table 5.

Table 5. Equation (3) parameters for the different calibration fluid(s), where $\rho_{\mathrm{M}}$ (the density of the Hastelloy U-tube) is $8.89 \mathrm{~g} \cdot \mathrm{cm}^{-3}$ [10].

\begin{tabular}{cccc}
\hline & Water & Toluene & Water + Toluene \\
\hline$S_{00}$ & 0.89235 & 0.89163 & 0.89184 \\
$\alpha_{\mathrm{V}}\left(\mathrm{K}^{-1}\right)$ & $0.36267 \mathrm{E}-04$ & $0.39226 \mathrm{E}-04$ & $0.38221 \mathrm{E}-04$ \\
$\beta_{\mathrm{V}}\left(\mathrm{kPa}^{-1}\right)$ & $-0.33545 \mathrm{E}-07$ & $-0.13360 \mathrm{E}-06$ & $-0.70565 \mathrm{E}-07$ \\
$\beta_{\tau}\left(\mathrm{kPa}^{-1}\right)$ & $-0.12206 \mathrm{E}-07$ & $-0.19390 \mathrm{E}-07$ & $-0.14889 \mathrm{E}-07$ \\
\hline
\end{tabular}

To understand how well each calibration equation fit the available calibration data, average absolute deviations of data from each of the six equations are given in Table 6 . The table indicates that the polynomial equation does a good job representing the fluid(s) to which it is fit, but not fluids that are not included in the calibration data set. In contrast, the May et al. [1] equation consistently fits the fluids well, with only slightly higher deviations if the fluid is not included in the calibration data set.

Table 6. Average absolute deviations (AAD) of calibration data from the different correlations.

\begin{tabular}{lcclc}
\hline & \multicolumn{2}{c}{ Nine-term polynomial } & \multicolumn{2}{c}{ May et al. equation } \\
\hline Calibration Fluid(s) & $\begin{array}{l}\text { AAD of Water Data } \\
\text { from Correlation } \\
\left(\mathrm{kg} \cdot \mathrm{m}^{-3}\right)\end{array}$ & $\begin{array}{l}\text { AAD of Toluene } \\
\text { Data from } \\
\text { Correlation }\left(\mathrm{kg} \cdot \mathrm{m}^{-3}\right)\end{array}$ & $\begin{array}{l}\text { AAD of Water Data } \\
\text { from Correlation } \\
\left(\mathrm{kg} \cdot \mathrm{m}^{-3}\right)\end{array}$ & $\begin{array}{l}\text { AAD of Toluene } \\
\text { Data from } \\
\text { Correlation }\left(\mathrm{kg} \cdot \mathrm{m}^{-3}\right)\end{array}$ \\
Water & 0.03 & 30.42 & 0.12 & 0.24 \\
Toluene & 13.65 & 0.04 & 0.30 & 0.08 \\
Water + toluene & 0.11 & 0.08 & 0.18 & 0.13 \\
\hline
\end{tabular}

\section{Equations Applied to Lubricant Data}

The main goal of this work was to explore how different combinations of calibration fluids and different calibration equations would affect the calculated densities of measured samples. Here, densities of three lubricants were each calculated based on six different calibration equations so that the outcomes could be compared. Figure 1, parts a-c, illustrates deviations of the densities calculated with the May et al. [1] equation from densities calculated with the nine-term polynomial when both equations were correlated using the combined water and toluene calibration data. Figure 1 shows that the differences in the densities calculated with the nine-term polynomial versus the May et al. equation [1] are greatest for POE5, but still mostly within $\pm 0.4 \mathrm{~kg} \cdot \mathrm{m}^{-3}$, and all within $1.2 \mathrm{~kg} \cdot \mathrm{m}^{-3}$ (the maximum uncertainty of the measurements).

Figure 2, parts a-c, shows differences in the densities calculated with the nine-term polynomial equation based on each of the pure fluids relative to densities calculated with the nine-term equation correlated with the combined data of water and toluene. The densities calculated with the equation based on both water and toluene serve as the baseline. The figure parts show that very large differences (some as great as $20 \mathrm{~kg} \cdot \mathrm{m}^{-3}$ ) in the calculated densities for a given lubricant can arise depending upon the calibration fluid(s) that are used in the correlation of the nine-term polynomial equation. 


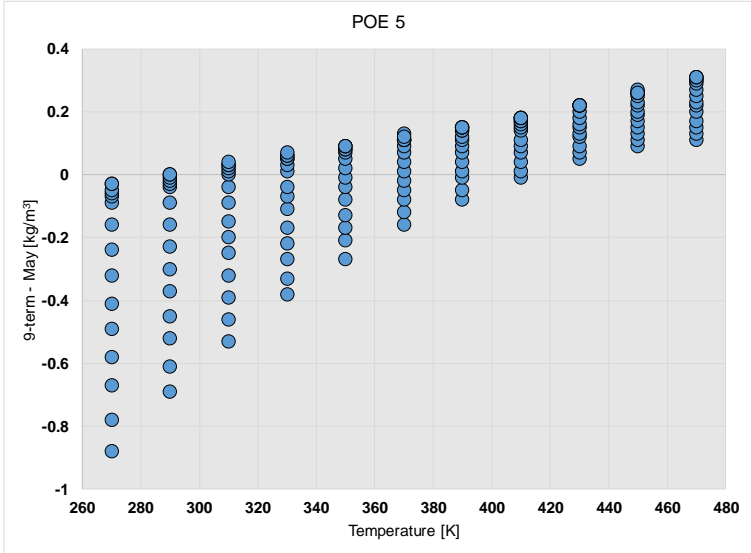

a.

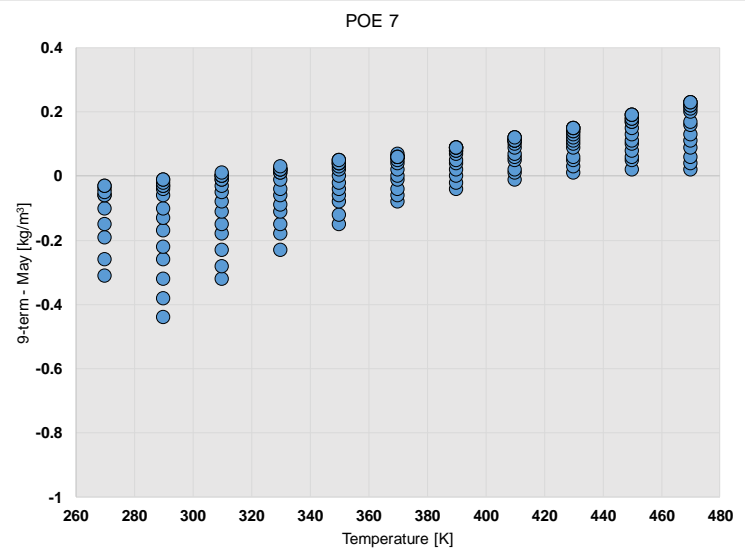

b.

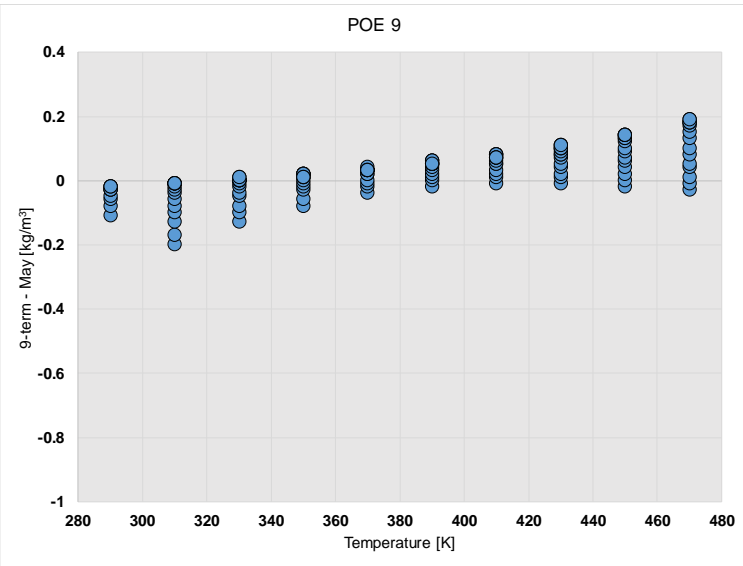

c.

Fig. 1. Difference in lubricant densities calculated with the nine-term polynomial equation from those calculated with the May et al. [1] equation when both equations have been correlated with the combined toluene and water calibration data. 


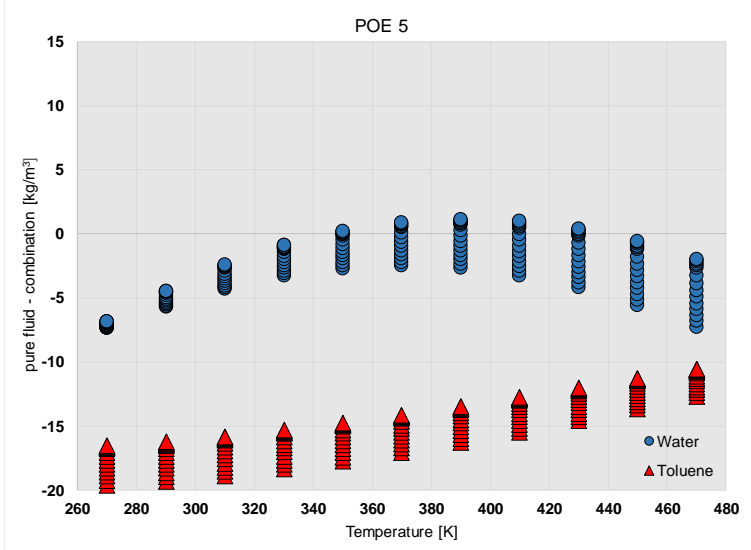

a.

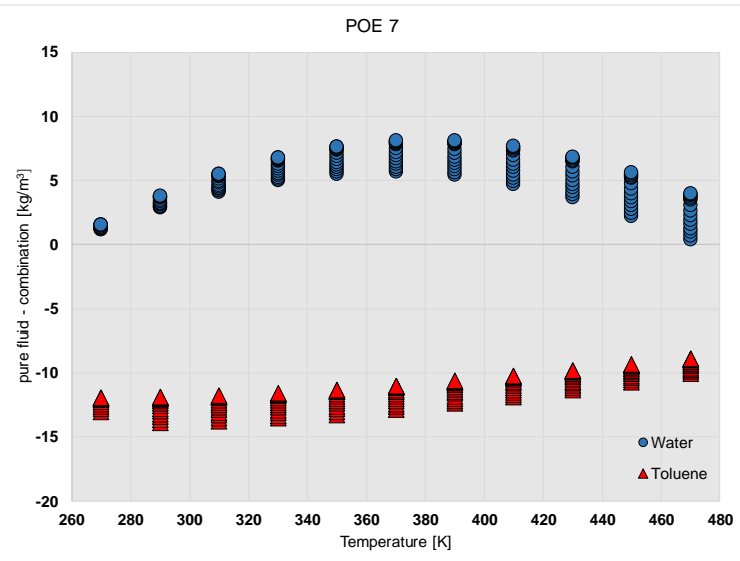

b.

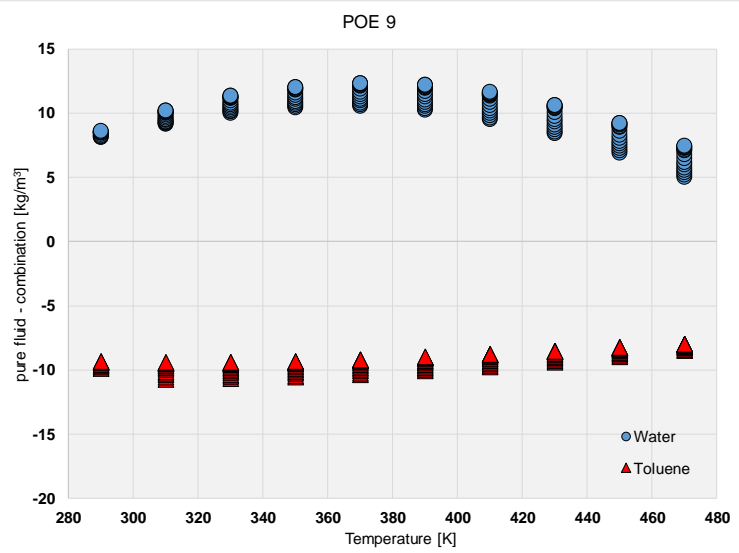

c.

Fig. 2. Difference in lubricant densities calculated with the nine-term equation correlated with only water or toluene from those calculated with nine-term equation correlated with the combination of toluene and water calibration data. 
Figure 3, parts a-c, is akin to Fig. 2, but calculations were based on the May et al. [1] equation. Here, differences in the densities calculated for the each of the lubricants based on the various calibration fluid(s) are not nearly as great as for the nine-term equation.

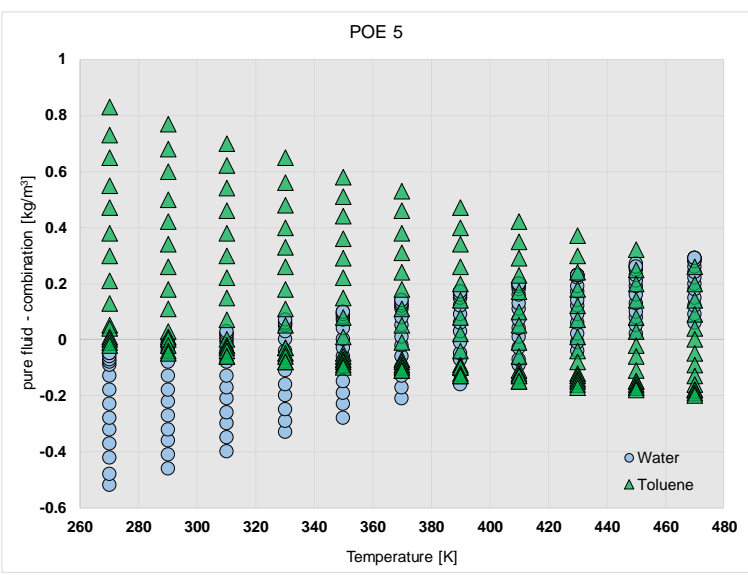

a.

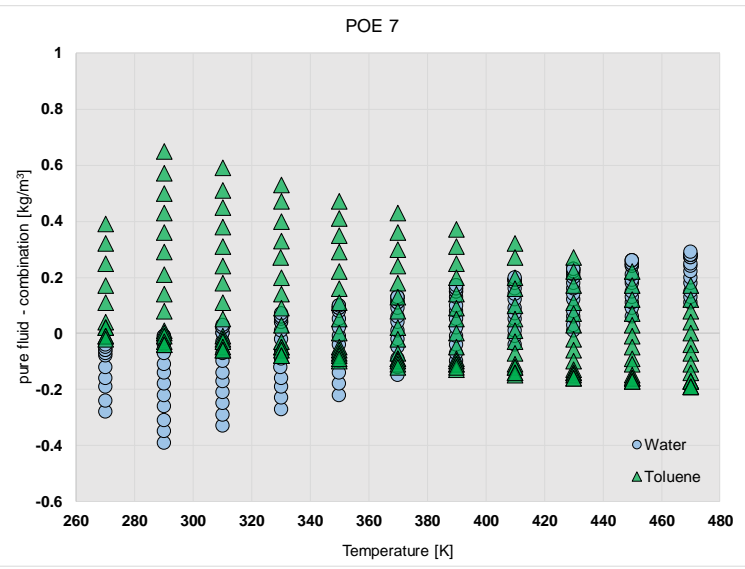

b.

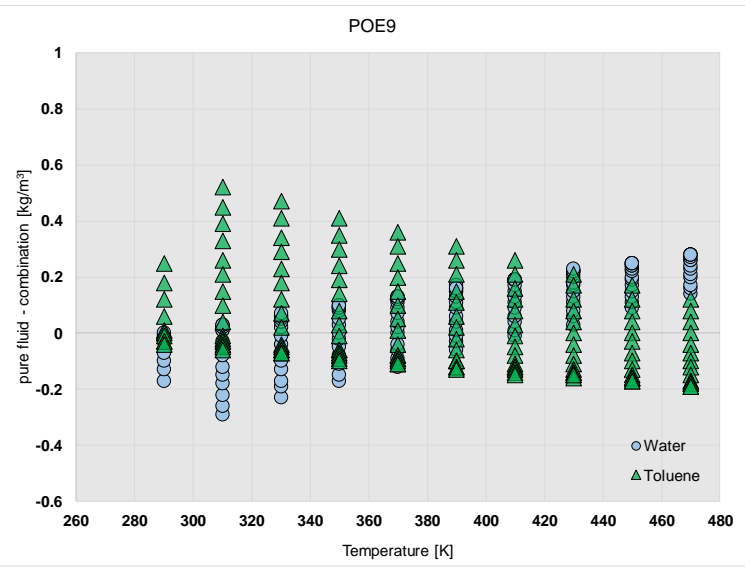

c.

Fig. 3. Difference in lubricant densities calculated with the May et al. [1] equation correlated with only water or toluene from those calculated with the May equation correlated with the combination of toluene and water calibration data. 


\section{Discussion}

As mentioned previously, measurements with U-tube densimeters are not absolute, and the accuracy of those measurements rests largely on the choice of calibration fluid(s) used to adjust the instrument. It follows that the "best" calibration fluids for the measurement of a given sample would be those that are certified reference materials (CRM) or have very accurate equations of state and will have densities (at each state point) very similar to the sample(s) that will be measured. This is not always possible, as a sample may be under study because little or no data are available for the fluid. Thus, it is generally wise to pick a calibration fluid or fluids that cover a large range of densities over the temperature and pressure ranges where samples are to be measured.

To better understand or interpret the results of this study, it is useful to know some of the physical properties of the calibration fluids as well as the lubricants measured. Figure 4 illustrates the density ranges of toluene, water, POE5, and POE9 as a function of pressure over the temperature ranges of this study. The density of POE7 would fall between those of POE5 and POE9 were it included. This figure shows that it is impossible to cover the complete density surface of POE5 with either toluene or water or a combination of the two as calibration fluids. The density surface of POE5 shows no overlap with that of toluene and is only partially covered by that of water. The surface of POE9, however, is almost completely covered by the combination of toluene and water, as would be the surface of POE7 were it shown. This helps to explain the larger deviations of the POE5 data as compared to data of POE7 and POE9 in Figs. 1-3.

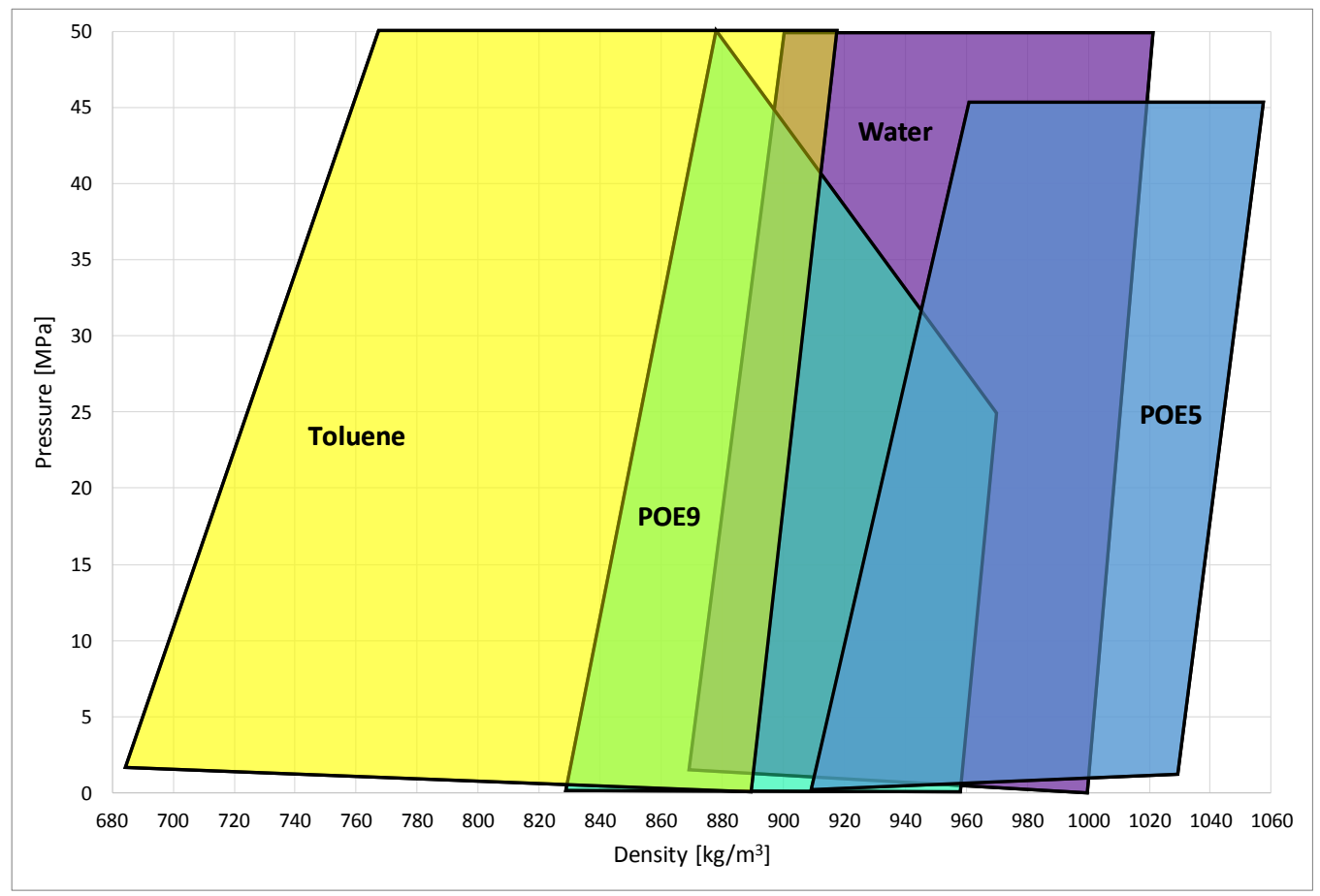

Fig. 4. Density surfaces of toluene, water, POE5, and POE9 measured in this work.

All three of the measured lubricants have viscosities far greater than that of toluene or water. For comparison, the ranges of viscosities of the lubricants, toluene, and water over the temperature and pressures of this study are given in Table $7[11,12]$. From the table, the viscosities of toluene and water are approximately two orders of magnitude less than those of the lubricants. The large difference in the viscosities of the calibration fluids versus the measured samples is problematic. The period of oscillation of 
the vibrating tube is affected by the viscosity of the fluid in the tube. If the viscosities of the calibration fluids are very different from those of the measured samples, results may be less accurate. Unfortunately, there are few, if any, high-viscosity density calibration fluids available that cover large ranges in temperature.

There is a viscosity correction recommended by Anton Paar $^{1}$ (the manufacturer of the U-tube used for this work), but it requires having a viscosity correlation for the fluid that is being studied. The correction is as follows

$$
\frac{\Delta \rho}{\rho}=(-0.5+0.45 \sqrt{\eta}) \times 10^{-4}
$$

where $\eta$ is the dynamic viscosity of the sample in $\mathrm{mPa} \cdot \mathrm{s}$. This correction was applied in Outcalt [8] and found to be a maximum of $0.7 \mathrm{~kg} \cdot \mathrm{m}^{-3}$ for POE5 at $270 \mathrm{~K}$ and $50 \mathrm{MPa}$. It is not included in the density values plotted in this work.

Table 7. Viscosity range of the calibration fluids and lubricants in the temperature and pressure ranges of this study.

\begin{tabular}{cc}
\hline Fluid & Viscosity Range $(\mathrm{mPa} \cdot \mathrm{s})$ \\
\hline Toluene & $0.01-1.2$ \\
Water & $0.02-1.4$ \\
POE5 & $1.3-260$ \\
POE7 & $1.3-227$ \\
POE9 & $2.2-137$ \\
\hline
\end{tabular}

Figure 1, parts a-c, illustrates that the differences in the densities calculated with Eq. (1) versus Eq. (3) are small. This helps to lend confidence to the measurement results calculated from the calibration equations formulated using both water and toluene as calibration fluids.

Figure 2, parts a-c, shows that with the nine-term equation, results for the calculated densities of the lubricants are very different when just one of the calibration fluids is used to correlate the equation. This is an indication that the functional form of the equation does not extrapolate well beyond the density range of the calibration fluids. In contrast, Figure 3, parts a-c, shows that calculated results from the May et al. equation [1] (regardless of the calibration fluid(s) used in the formulation) are much more consistent. The May et al. [1] equation is based on the equation of motion for a freely vibrating uniform cantilever. It is therefore, a model based on the physical behavior of the U-tube, whereas the nine-term polynomial expansion is largely empirical. This is one of the reasons that it behaves more consistently in its prediction of the densities of the lubricants regardless of the calibration fluid(s) used in the correlation.

\section{Conclusions}

The effects of the choices of calibration fluid(s) and calibration equation on the calculated densities of three lubricants were studied in this work. The results show that the two equations studied behave consistently when both are formulated with both toluene and water and that the May et al. [1] equation behaves consistently regardless of the choice of fluid(s).

This work illustrates that to make highly accurate measurements of density with the vibrating-tube method, the variables of calibration fluid(s) and calibration equation must be considered with great care, particularly when the samples being measured are of very different viscosity than the calibration fluid(s). A given calibration equation might accurately model a single calibration fluid, but that does not necessarily mean that the densities of measured samples derived from that combination will be accurate. Some

${ }^{1}$ To describe materials and experimental procedures adequately, it is occasionally necessary to identify commercial products by manufacturers' names or labels. In no instance does such identification imply endorsement by the National Institute of Standards and Technology, nor does it imply that the particular product or equipment is necessarily the best available for the purpose. 
combinations of calibration fluid and calibration equation extrapolate accurately in some instances; however, this is not always the case. The availability of calibration fluids of certified reference quality that cover large temperature ranges $(150 \mathrm{~K}$ or more) in viscosity ranges above $1 \mathrm{mPa} \cdot \mathrm{s}$ and/or densities above $1200 \mathrm{~kg} \cdot \mathrm{m}^{-3}$ would be helpful in making more accurate measurements of samples with similar properties.

\section{References}

[1] May EF, Tay WJ, Nania M, Aleji A, Al-Ghafri S, Trusler JPM (2014) Physical apparatus parameters and model for vibrating tube densimeters at pressures to $140 \mathrm{MPa}$ and temperatures to $473 \mathrm{~K}$. Review of Scientific Instruments 85(9):095111. https://doi.org/10.1063/1.4894469

[2] Bouchot C, Richon D (2001) An enhanced method to calibrate vibrating tube densimeters. Fluid Phase Equilibria 191(1-2):189208. https://doi.org/10.1016/S0378-3812(01)00627-6

[3] Holcomb CD , Outcalt SL (1998) A theoretically-based calibration and evaluation procedure for vibrating-tube densimeters. Fluid Phase Equilibria 150:815-827. https://doi.org/10.1016/S0378-3812(98)00362-8

[4] Lagourette B, Boned C, Saint-Guirons H, Xans P, Zhou H (1992) Densimeter calibration method versus temperature and pressure. Meas Sci Technol 3(8):699-703. https://doi.org/10.1088/0957-0233/3/8/002

[5] Lampreia IMS , de Castro CAN (2011) A new and reliable calibration method for vibrating tube densimeters over wide ranges of temperature and pressure. J Chem Thermodyn 43(4):537-545. https://doi.org/10.1016/j.jct.2010.11.002

[6] Sousa AT, Fialho PS, de Castro CAN, Tufeu R, Le Neindre B (1992) Density of HCFC 142b and of its mixture with HCFC 22. Fluid Phase Equilibria 80:213-225. https://doi.org/10.1016/0378-3812(92)87069-Y

[7] Outcalt SL , McLinden MO (2007) Automated Densimeter for the Rapid Characterization of Industrial Fluids. Ind Eng Chem Res 46(24):8264-8269. https://doi.org/10.1021/ie07079le

[8] Outcalt SL (2018) Compressed-liquid Density Measurements of Four Polyol Ester-Based Lubricants. Energy Fuels 32(3):37753782. https://doi.org/10.1021/acs.energyfuels.8b00050

[9] Boggs PT, Byrd RH, Rogers JE, Schnabel RB (1992) User's Reference Guide for ODRPACK Version 2.01 Software for Weighted Orthogonal Distance Regression. (National Institute of Standards and Technology, Gaithersburg, Maryland), NIST Interagency/Internal Report (NISTIR) 4834. https://doi.org/10.6028/NIST.IR.4834

[10] Haynes International (2017) Hastelloy C-276 Alloy. Available at http://haynesintl.com/docs/default-source/pdfs/new-alloybrochures/corrosion-resistant-alloys/brochures/c-276.pdf?sfvrsn=4/

[11] Lemmon EW, Huber ML, McLinden MO (2014) NIST Standard Reference Database 23: Reference Fluid Thermodynamic and Transport Properties-REFPROP, Version 9.11 (National Institute of Standards and Technology, Standard Reference Data Program, Gaithersburg). Available at http://www.nist.gov/srd/nist23.htm

[12] Laesecke A, Junker C, Lauria DS (2018) Viscosity Measurements of Three Base Oils and One Fully Formulated Lubricant and New Viscosity Correlations for the Calibration Liquid Squalane. in review.

About the author: Stephanie L. Outcalt is a chemical engineer in the Applied Chemical and Materials Division at the National Institute of Standards and Technology in Boulder, CO. The National Institute of Standards and Technology is an agency of the U.S. Department of Commerce. 